Estudios de la Paz y el Conflicto

Revista Latinoamericana

IUDPAS-UNAH

Número Especial 1, pp. 85-101

ISSN-e: 2707-8922 / ISSN: 2707-8914

DOI: $10.5377 /$ rlpc.v0i0.9505

Anual 2019

\title{
MARÍA CANO. AÚN TENGO LA PALABRA. APROXIMACIONES CORPORALES A LA VIDA DE UNA MUJER QUE ENCARNA LAS LUCHAS EN COLOMBIA, DESDE UN EJERCICIO DE MEMORIA ESTÉTICA
}

MARÍA CANO. I STILL HAVE A VOICE. AN APPROACH FROM THE BODY TO THE LIFE OF A WOMAN WHO EMBODIES COLOMBIAN STRUGGLES, THROUGH AN EXERCISE OF AESTHETIC MEMORY

Marybel Acevedo Fandiño

Docente de la ASAB, Universidad Externado de Colombia y Universidad del Rosario marybelacevedo@,gmail.com

Karen Fajardo Capador

Colectivo Extempora Danza

krenfajardo@gmail.com

Daniela García Hernández

Colectivo Extempora Danza dali.gahe@gmail.com

Mónica Alejandra Romero Pérez Colectivo Extempora Danza monica.romerop1@gmail.com

Mariana Velandia Nova Colectivo Extempora Danza almarvenova@gmail.com

Cómo citar / citation

Acevedo, M.; Fajardo, K.; García, D.; Romero, M.A. y Velandia, M. (2019). "María Cano. Aún tengo la palabra. Aproximaciones corporales a la vida de una mujer que encarna las luchas en Colombia, desde un ejercicio de memoria estética", Estudios de la Paz y el Conflicto, Revista Latinoamericana, Número Especial 1, 85-101. DOI: 10.5377/rlpc.v0i0.9505 


\title{
Resumen
}

El presente trabajo de investigación es una propuesta de paz y reconciliación por medio del lenguaje escénico de la danza teatro, que anuda la vida de María Cano y la posibilidad de construir una memoria estética que reconozca los sujetos múltiples, complejos, agenciales y fronterizos. Seres que han sido invisibilizados por las narrativas dominantes a través de una política del ocultamiento y de producción de ausencias.

\section{Palabras clave}

Estrategias de paz; memoria estética; reflexiones corporales; danza; transformación de la experiencia; María Cano.

\begin{abstract}
This research work is a proposal for peace and reconciliation through the scenic language of contemporary dance that ties the life of María Cano and the possibility of building an aesthetic memory that recognizes multiple, complex, agency and border subjects. Beings that have been made invisible by the dominant narratives through a policy of concealment and the production of absence.
\end{abstract}

\section{Keywords}

Strategies for peace; aesthetic memory; embodiment reflection; dance; experience transformation; María Cano.

\section{INTRODUCCIÓN}

Mi corazón ya no late

Sólo aletea

Todo corazón de mujer

Lleva un temblor de nido ${ }^{I}$

Pensemos en Colombia hace 100 años, ¿cómo hemos hecho memoria de hitos históricos como la huelga de las textileras o la masacre de las bananeras? He aquí una estética ${ }^{2}$ del ocultamiento, que ha velado vidas como la de María Cano la flor del trabajo. Militante, activista, sindicalista, soñadora. Es por ello que, a partir de la vida de esta mujer, construimos una propuesta de estrategia de paz que se piensa los procesos de reconciliación desde una memoria hecha con el cuerpo, el movimiento y el lenguaje escénico: un ejercicio de memoria estética. Presentamos entonces, los resultados de la puesta en práctica de este proceso de investigación-creación que se propuso desarticular las narrativas de una única historia, para develar, a través de la danza, la vida de una mujer que construyó su vida política desde la subalternidad, la historia múltiple y el intento de transgredir los patrones de dominio y control de unos cuerpos sobre otros.

\footnotetext{
${ }^{1}$ Texto a dos manos, entre María Cano y Marybel Acevedo.

${ }^{2}$ A lo largo del artículo comprendemos estética como un concepto que desborda la esfera de las artes, pues hace referencia a los modos posibles de la experiencia sensible en el mundo. En correspondencia, el terreno de las artes, al reproducir, deconstruir y construir unos órdenes de lo sensible, dan consistencia a lo que ocurre en el terreno de lo político, lo ético y lo epistémico. En esta doble vía enunciamos los conceptos de estética del ocultamiento y de memoria estética.

Estudios de la Paz y el Conflicto, Revista Latinoamericana, IUDPAS-UNAH, Número Especial 1, 2019, pp. 85-101. DOI: $10.5377 /$ rlpc.v0i0.9505
} 
La pregunta inicial de esta indagación supone adentrarnos en aquella Colombia de inicios del siglo XX que presentaba transformaciones importantes en el desarrollo económico, social y político. Según Gallor (1988) esta fue una época de grandes irrupciones industriales y manufactureras, de cambios en las formas de vida urbano-rurales; de emergencia de nuevos sectores de trabajadores que ingresarían a engrosar los procesos de proletarización locales; de guerras que irían prolongándose y transformándose en ciclos interminables que hasta la actualidad resuenan con un eco desgastado; de crecimiento de obras públicas, férreas y marítimas; de reforzamiento de una estructura agraria desigual y falocéntrica; de inserción del capital financiero y transnacional al escenario nacional, y del "establecimiento de un modelo económico capitalista dependiente" (Gallor, 1988: 289).

Ante estos agravios y patrones de reestructuración societal, existieron grupos poblacionales que cobrarían fuerza en la esfera pública de acuerdo con sus reivindicaciones y exigencias como los cuerpos femeninos. En ese sentido, pese a que las mujeres entrarían a incorporarse paulatinamente al sistema productivo en las industrias textiles y cerveceras, sus derechos sociopolíticos eran relegados y marginalizados (educación, salario, patrimonio, etc). Esta dinámica de exclusión incentivó a que las mujeres se organizaran para garantizar sus derechos en lo que hasta ese momento se gestaba como movimiento sindical. De ahí que esta investigación busque pasar del ocultamiento dado por una sociedad patriarcal, a la develación del papel de mujeres como María en la historia colombiana y la importancia de su memoria y reivindicación en las luchas que se pelean hoy.

Estas memorias nos permitieron comprender al cuerpo como archivo vivo (Bidaseca, 2018; Antonacci, 2016) dentro del proceso creativo, el cual estuvo tejido por lecturas de mundo que reivindican las epistemologías del sur, los feminismos contrahegemónicos y las apuestas descoloniales. En efecto, la perspectiva relacional, situada e interseccional nos permitió indagar por esas voces subalternas que han sufrido la violencia estructural y las cadenas de exclusiones propias del colonialismo, racismo, patriarcado y capitalismo en la historia reciente; así como encontrar caminos para narrar e interpelarnos por nuestra historia pluriversa desde cuerpos que rememoran, transforman y significan el mundo. Este lienzo parte de ser una apuesta desde la estética descolonial que, desde su acción sentipensante, intenta fisurar las formas dominantes de construcción de conocimiento, producción de historia y cimentación de "otredad".

A partir de la vida de María Cano y su realidad se expone una breve contextualización sobre los aspectos socio políticos y económicos de Colombia a principios del siglo XX y la inserción de los movimientos de mujeres y obreros-sindicalistas como enjambre de la vida de Cano. Después, desarrollamos los conceptos emergentes del proceso de investigacióncreación en danza-teatro: en primer lugar, se desarrolla la estética del ocultamiento vinculado con el concepto de Sousa producción de ausencias; en segundo lugar, se abordará el cuerpo como flujo y territorio de las realidades kinésicas ${ }^{3}$ en el que confluyen distintas temporalidades acordadas como pasadas y presentes; en el tercer lugar, mostraremos la potencialidad del ejercicio ético y crítico de la memoria estética en el reconocimiento,

\footnotetext{
${ }^{3}$ Realidad kinésica: movimiento natural que tiene unas particularidades del contexto. Al ser consciente y estudiado este movimiento se transforma en material corpóreo para elaborar coreografías. Allí, el intérprete se aproxima a una experiencia corporal de un pasado. El término kinesfera fue acuñado por el coreógrafo e investigador Rudolf von Laban (1994), este alude al cuerpo en su relación con la espacialidad personal. Estudios de la Paz y el Conflicto, Revista Latinoamericana, IUDPAS-UNAH, Número Especial 1, 2019, pp. 85-101. DOI: 10.5377/rlpc.v0i0.9505
} 
transformación y devenir de los $\operatorname{sujetos}^{4}$ que investigan y crean su propia historia. Finalmente, reflexionamos sobre el arte como apuesta política de reconciliación societal.

\section{METODOLOGÍA}

María Cano, Aún tengo la palabra, relaciona diferentes áreas de conocimiento que incluye investigación en ciencias sociales y la construcción escénica desde el lenguaje del movimiento. Permite organizar los elementos dramatúrgicos generales de la puesta en escena y configurar un estilo específico para el montaje. La estructura del montaje contiene cuatro fases en el proceso de composición que se están desarrollando en simultáneo (Figura 1):

\section{Figura 1. Estructura Creativa}

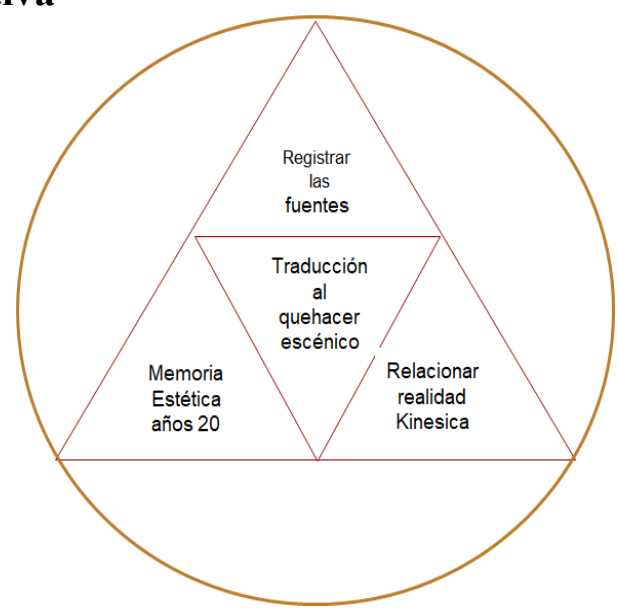

Gráfica 1. Realizado por Marybel Acevedo para este documento (2019)

Por un lado, el registro de fuentes consiste en la recolección de archivos que posibiliten entender el período histórico y la vida de María Cano. Por otro lado, el análisis de la memoria estética de los años 20, fase que supone reconocer, proponer y apropiarse de códigos corporales que re-creen y reflejen la narrativa particular de la vida de Cano y el contexto en el cual se desarrolla.

Paralelamente desarrollamos la fase denominada realidad kinésica comprendida como la aprehensión de la realidad sensible, donde los gestos, sonoridades y texturas, disponen unos espacios y el ser de quienes lo habitan; permitiéndonos entrar en un laboratorio de creación,

\footnotetext{
${ }^{4}$ El presente escrito tiene una posición política y ética respecto al uso del lenguaje. Como colectivo hemos decidido apostar por una lingüística feminista la cual sostiene que el lenguaje es un campo de tensión política en donde los seres humanos somos configurados y configuramos la realidad y tiene un carácter ecoevolutivo y dinámico. Además, es coherente con las tesis desarrolladas en este texto. Así, consideramos que el carácter universalizante y específico del masculino gramatical es intencional y organiza los modos relacionales e interaccionales en un contexto. Es por ello que usted encontrará el uso de la " $\mathrm{x}$ " en algunas palabras tales como: todos, sujetos, compañeros; incluyendo la diversidad de géneros humanos desbordando el binario masculinofemenino. Ahora bien, en algunos casos utilizamos exclusivamente el femenino gramatical para referirnos a los procesos de creación y/o reflexión del grupo Extémpora Danza en el que participamos en su mayoría mujeres. Para profundizar más sobre la problematización del lenguaje sexista los invitamos a revisar las tesis de las teóricas Norbeck, H (2013); Adokarley, B (2015); Cameron, D (1985, 1992).

Estudios de la Paz y el Conflicto, Revista Latinoamericana, IUDPAS-UNAH, Número Especial 1, 2019, pp. 85-101. DOI: 10.5377/rlpc.v0i0.9505
} 
que desemboca en gestación de imágenes, partituras de movimiento y elementos dramatúrgicos.

Por último, encontramos la traducción al quehacer escénico ${ }^{5}$, fase en la cual se realiza la confluencia de los anteriores momentos del proyecto que sitúan en un devenir espaciotemporal a cada participante como pauta para entretejer memoria y movimiento. Este entretejido se elaboró con la escritura personal sobre el proceso de investigación-creación fundamentada en el cruce de distintas fuentes sobre la vida de María Cano; las realidades de las mujeres; el movimiento obrero-sindicalista; y las pautas de movimiento con la experiencia personal. De este modo, los escritos se denominaron relatos etnográficos como apuesta metodológica singular y colectiva que permitió encontrar sentidos corporales y sensitivos de la vivencia en la aprehensión del pasado.

\section{DISCUSIONES Y RESULTADOS DEL PROCESO}

\section{Preludio entre el silencio y la voz. María Cano y la estética del ocultamiento}

A inicios del siglo XX voces subalternas y movimientos sociales cobraron fuerza en la esfera pública nacional ante los distintos procesos de reestructuración societal que se configuraban en Colombia. El agenciamiento de las mujeres en los movimientos organizativos sindicales $\mathrm{y}$ sociales es un ejemplo claro de los campos que se iban arando a partir de las reivindicaciones de corporalidades diversas y el cuestionamiento de los roles del sistema sexo-genérico en el país.

Recordamos la gran huelga de textileras en Bello, Antioquia, en 1920 liderada por Betsabé Espinal; acontecimiento que duró tres semanas y convocó más de 400 trabajadoras en uno de los municipios más importantes de textiles en Colombia. Como ella existieron otras mujeres que participaron en estos escenarios de lucha política desde sus espacios de conocimiento e intuición. Una de ellas fue Débora Arango, artista que subvirtió el orden y fue censurada por hacer desnudos de prostitutas, trabajo que era sentenciado y juzgado como indebido en la esfera social a pesar de ser una práctica de consumo masculino. También, encontramos a Ofelia Uribe fundadora de la revista Agitación Femenina en la que realizaba publicaciones abogando por el sufragio femenino y luchando para que hombres y mujeres tuvieran los mismos derechos; caso similar al de María Currea, enfermera y una de las primeras mujeres que ocupó un cargo público.

Este andamiaje de agitación femenina se vio reflejado, también, en el grito subversivo de una mujer antioqueña que se sembró en tierra fértil: María de los Ángeles Cano Márquez. María nació el 12 de agosto de 1887, formándose a la luz de las ideas liberales, del conocimiento filosófico de su padre Rodolfo Cano, y del saber intuitivo y profundo del mundo sensible e "invisible" transmitido por su madre Amelia Márquez. Entre bibliotecas, tertulias y jardines fue construyendo su mirada que vería, desde su infancia, los intentos de

\footnotetext{
${ }^{5}$ Traducción al quehacer escénico: la interpretación del contexto del siglo XX resignificada dentro de la escena. Permite elaborar narrativas propias en cada uno de los intérpretes bailarines y en la obra en general. Hay una apuesta en esta traducción por permitir que se restaure el pasado con la interpretación de los elementos característicos de la época, para situarlos en el movimiento espacio-temporal de hoy. Esto supone considerar la paradoja que implica una aproximación sensible al pasado, su reinterpretación y los sentidos que transitan en estos.

Estudios de la Paz y el Conflicto, Revista Latinoamericana, IUDPAS-UNAH, Número Especial 1, 2019, pp. 85-101. DOI: 10.5377/rlpc.v0i0.9505
} 
silenciamiento, persecución y hostigamiento hacia su nodo familiar por el continuum de violencias políticas desatadas en el país. Más su paso por las geografías biodiversas de Colombia y su figura pública recrearían su mirada y la enraizarían a la tierra para avivar su voz.

\section{Fotografía 1. La huida.}

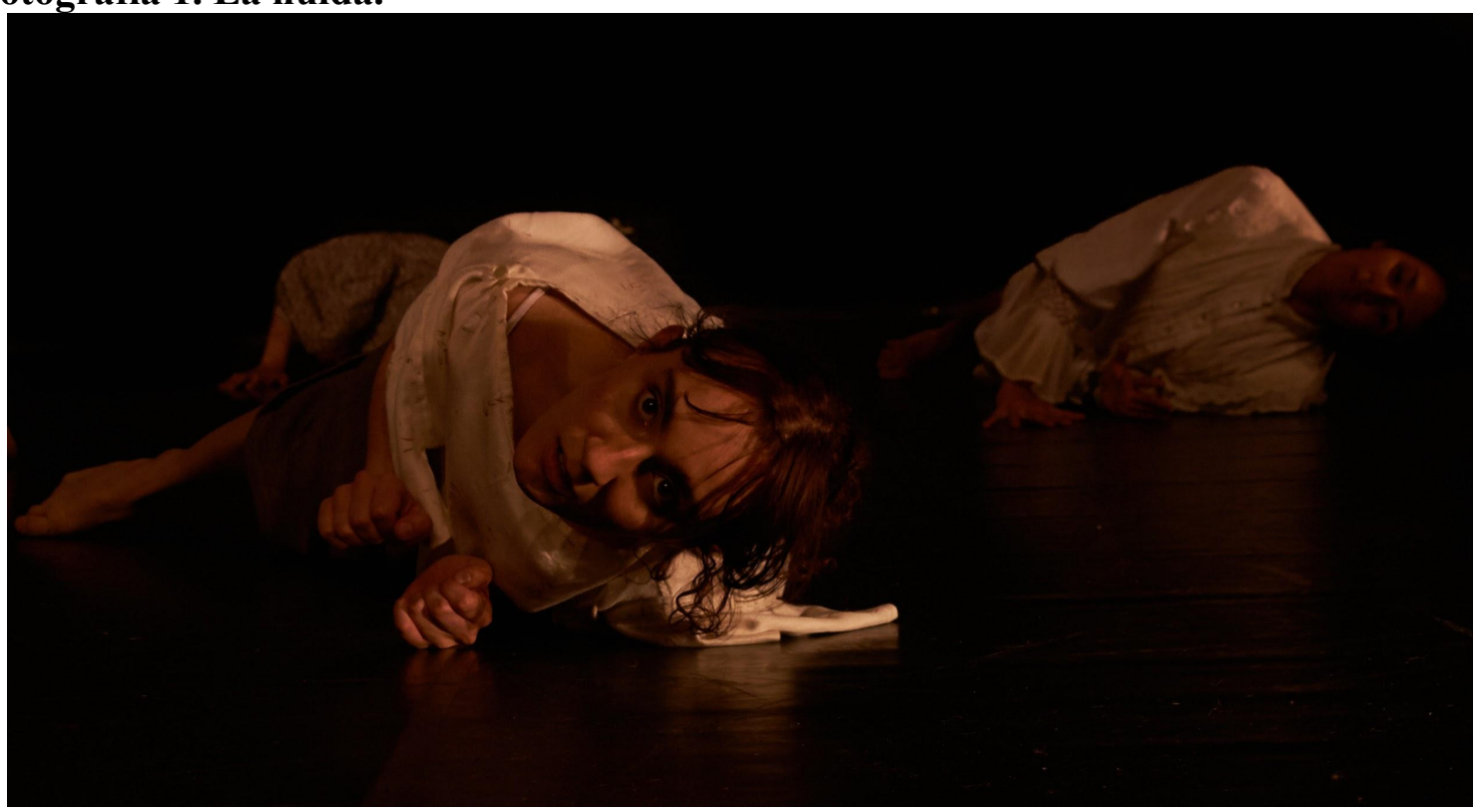

Fuente: Danilo Rodríguez; Intérpretes Mariana Velandia y Daniela García. Bogotá. 2019

María Cano aparece en la esfera pública transgrediendo lo que hasta ese momento era considerado aceptable en el campo político y sociocultural, lugar en donde la mujer no tenía voz y, menos, quien defendía y abogaba por el derecho a la vida, los derechos civiles y laborales de campesinos, trabajadores industriales y mujeres, así como por el fortalecimiento y el impulso de conciencias críticas. El siguiente fragmento del discurso de María Cano, por ejemplo, alude a sus intentos aguerridos por sembrar la objeción de conciencia sobre el servicio militar:

Todo corazón de mujer lleva un temblor de nido. ¿No sentís en vosotras el impulso al grito en defensa de vuestro tesoro? Sois madres, hermanas, novias, y sobre todo eso, sois la mujer. ¿Por qué no eleváis vuestra protesta, dulce pero firme? Son los hombres de mañana. Es la juventud sagrada. ¿No palpita en vuestras almas el grito? Quisiera que este mi grito de protesta y de súplica subiera el diapasón hasta lo infinito y cubriera luego con su onda sonora las almas, penetrándolas (Cano, 1924, tomado de ENS, 2007: 59)

Igualmente, la flor del trabajo, título que recibiría en sus años de agitación política, instó por la liberación de los presos políticos y asistió y participó en la creación del Partido Socialista Revolucionario (PSR) (ENS, 2007: 12). Luego de haber andado por las geografías agrestes del país, se situó en Bogotá donde escucharía "historias que la estremecían. En las casas de los obreros había niños enfermos de sarampión, adolescentes rendidos por la viruela y mujeres que trabajaban 20 horas diarias en trilladoras de café, fábricas de botones, jabones, sombreros, escobas, confecciones, tejidos, fósforos y calzado" (ENS, 2007: 13). Historias 
que afianzaron su convicción por un mundo más justo y serían la antesala de su acción política.

Recorriendo Remedios, Segovia, Boyacá, Honda, Barrancabermeja, Bogotá, llegó a Manizales. Allí, con sus pies enraizados en la tierra, se enfrentó a viva voz con las balas que intentaban dispersar la concentración presente en la plaza pública. Su palabra refleja a una mujer cuyos intentos de ser silenciada no la supieron agotar:

Hijos de virtuosos campesinos y abnegados obreros, ¿cómo podríais disparar al pecho de vuestros hermanos? Un día entregaréis los fusiles, volveréis al trabajo, y seréis vosotros aqui o en cualquier sitio de Colombia, quienes estaréis unidos, de pie valerosamente, oyendo el mensaje de las ideas que os harán libres (Discurso María Cano, plaza pública Manizales. Tomado de ENS, 2007: 16)

Esta mujer, que supo romper los moldes de la sociedad tradicional antioqueña, se caracterizaba por su pensamiento crítico y su humanidad desmedida. Sus críticas no solo respondían a los sistemas económicos y políticos nacionales, sino a las micro estructuras de poder al interior de la organización en la que participaba. Su interés no era extrapolar referentes de mundo occidentales, sino atender a las necesidades y demandas del proceso histórico colombiano padecido y construido por sujetos diversos y situados. En consecuencia, su voz se convertiría en ruido incómodo dentro de su propia organización de la cual sería apartada más adelante.

Particularmente su vida atravesada por persecuciones, encarcelamientos, aislamientos, exclusiones y autoritarismos, sembró en ella una figura silenciosa y privada, pero potencialmente creativa y reflexiva. El siguiente fragmento hace parte del último texto que Cano pública y responde a la conmemoración del día de la mujer, a sabiendas que, para esta época, ya había sido expulsada del PSR.

Pronto hará cuarenta años que fui traída por las masas trabajadoras del país, en cuya amable compañía estuve mientras se consideró que podría serles de alguna utilidad. Y fui a confundirme con la gran marea popular — desde mi modesta posición de escritora de periódicos y revistasporque tenía la convicción entonces, como la tengo ahora de las razones justas que impulsaban al pueblo trabajador a luchar por sus legítimos intereses y de la necesidad que tenía y tiene todavía la nación de una fuerza social que unida y poderosa la redima de la miseria y la ignorancia. (Cano, 1960, citado por Robledo, 2017: 347)

En otras palabras, María Cano, como sendero poco visible, nos llevó a varios escenarios aproximativos de ocultamiento, escenarios grosso modo de producción de ausencias (Sousa, 2010). ¿Qué quiere decir ello? pues bien, el universo simbólico y material que nos constituye está marcado por una línea abissal (Sousa Santos, 2010; 2018a) creada a lo largo de la historia por las relaciones, procesos y patrones de poder colonial que atraviesan lo cotidiano. Dicha línea marca la pauta de diferenciación entre lo que se establece como sistemas, estructuras, acciones y sujetos potencialmente existentes y las exclusiones abismales ocultas que son producidas como inexistentes y/o carentes de validez y soporte en el horizonte de sentidos que "el mundo posee".

Boaventura de Sousa Santos $(2010 ; 2018 b)$, por ejemplo, propone cinco modos de producción de "la no existencia", es decir, cinco lógicas de producción de ausencias que distinguen la línea abissal. La vida de María Cano y la experiencia que hemos asumido a través del cuerpo, el movimiento y la danza, nos recuerdan varias de ellas. En primer lugar, 
percibimos la monocultura del tiempo lineal cuya lógica se inscribe en el entendimiento y la construcción de la historia bajo una dirección unívoca, lineal y progresiva.

En esta monocultura se construyen y legitiman representaciones de frontera que se amplían en una suerte de identificaciones binarias como lugar de lectura autoreferencial de mundo. Aquí podemos destacar la legitimación de los discursos binarios que propendían por ser y/o alcanzar una sociedad moderna (urbanizada e industrial) dejando de lado las prácticas "arcaicas" propias de la "sociedad tradicional" (sociedad rural, campesina, colona, etc), por ser una sociedad "civilizada" (blanca, empresarial) y alejarse de las formas de actuar, ser y vivir "salvajes" (indígenas, afrodescendientes, palenqueros, etc).

Incorporarnos al contexto social de la vida de María conllevó a aprender estos grandes marcos que plantean la historia como motor progresivo. Aquí encontramos una producción de ausencias referidas a las realidades obrero-campesinas en condiciones de desigualdad profunda y de transformaciones ontológicas en sus modos de vida.

A su vez, esta lógica "unitaria" de entender la historia es en sí misma una ausencia. En efecto, vimos que el ejercicio de construcción de memoria e historia, como campo en disputa, ha estado impregnado por una vasta cadena de silencios. Afonías que se encuentran en toda la margen fronteriza de la línea abissal, esa que vislumbra la centralización de las narrativas dominantes y la exclusión de otras maneras de percibir y construir el tiempo y la historia. Ya nos lo recordaba Trouillot (2011) al hablar sobre "el silenciamiento masivo del pasado a escala mundial como particularidad de las narrativas dominantes" (2011: 57). Hablar sobre María Cano y hacerla cuerpo-creación es comprender los mecanismos de silenciamiento a los que se vio enfrentada en vida, pero también a los mecanismos que la han ocultado paulatinamente de la historia oficial. Hallando, entonces, una estética del ocultamiento que ha marcado no sólo su vida, sino su recuerdo.

En segundo lugar, como relación próxima a esa estética del ocultamiento percibimos la lógica de la clasificación social o monocultura de la naturalización de las diferencias. En esta panacea ficcional vemos cómo se naturalizan formas de diferenciación de "lo otro" desde la exclusión. Es decir, la producción de ausencias está relacionada con la jerarquización y categorización de las diferencias en una supuesta normatividad y biologización de lo social. Allí, las categorías de sexo, raza, género, edad, cobran relevancia pues este lente forma una cadena de exclusiones o validaciones del ser.

En ese sentido, la flor del trabajo nos mostró una cadena de exclusiones y prácticas de ocultamiento a través de la realidad de la mujer y su rol social en el siglo XX en donde lo femenino, bajo las lógicas del sistema capitalista y patriarcal, se ha asociado con una idea de "sensibilidad, ternura y delicadeza". No obstante, María nos permitió sentir, a través de esa estética del ocultamiento, las formas de resiliencia y construcción descentrada al interior de la línea abissal, pues ella representa una voz unificadora de tantas mujeres que lucharon en este país, resaltando su papel en las grandes luchas obreras, en la formación política de partidos de la década y su participación en la defensa de los derechos de las mujeres. Así, la apuesta descentrada de María lleva consigo la reivindicación del espíritu femenino en la historia; espíritu cuyas subjetividades agenciales eran inconvenientes para el sistema de control y dominación de los cuerpos.

En este orden de ideas, el proceso de danza-creación desde la vida de esta activista nos sitúa en la estética del ocultamiento como lugar de producción de ausencias, pero también nos invita a aproximarnos a los diferentes procesos que producen la "no existencia". Aquí, nos sumergimos con otros elementos cruciales que han servido como vestíbulo de producción 
de ausencias, a saber: las prácticas de ocultamiento desde el arte. Estos han sido una pauta de invisibilización histórica de los procesos culturales y artísticos. Pauta que se compone de diferentes elementos como la implementación de manifestaciones culturales que son beneficiosas para el sistema por encima de las manifestaciones populares que lo subvierten y transgreden.

Dicha transgresión fronteriza de los cánones oficiales desde el arte vuelca la mirada sobre el proceso creativo de la obra María Cano. Aún tengo la palabra, pues queremos disponer una producción de ausencias y silencios, en presencias resignificadas desde la apuesta corporal. Allí, el cuerpo es un medio y fin de reconstrucción de memorias que esperan ser escuchadas por su vigencia. Comprendemos que el recordar no tiene una estructura cronológica y en ese caso se busca encontrar una manera de decir.

\section{Fotografía 2. Cuerpos silenciados.}

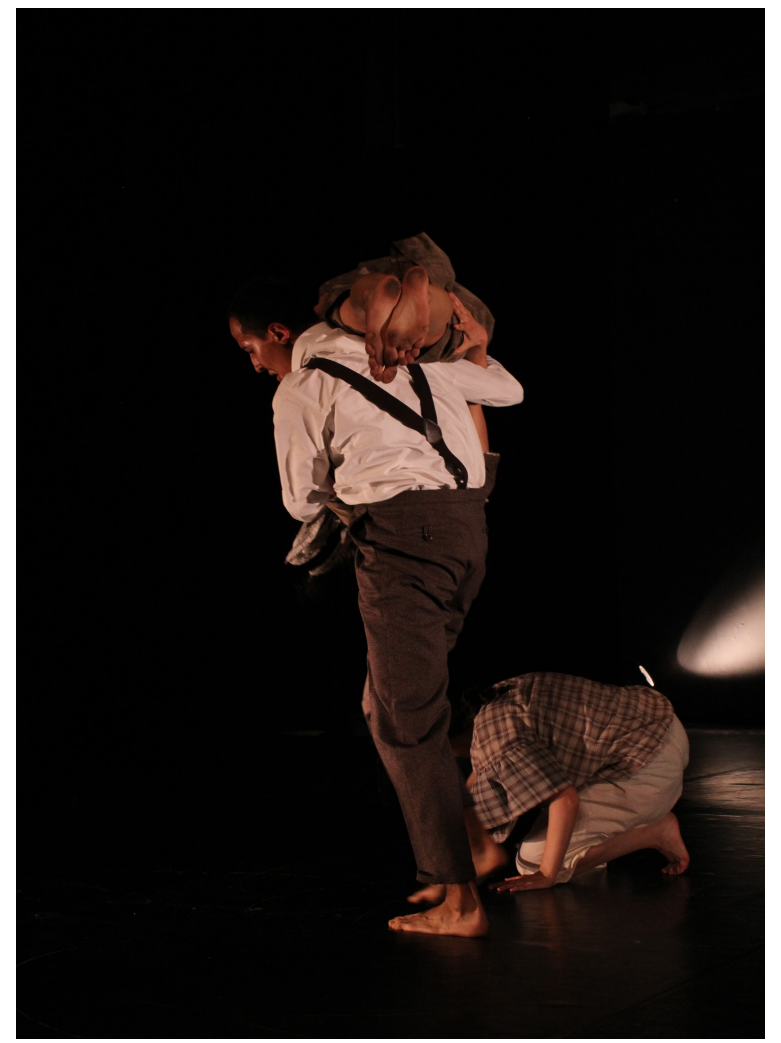

Fuente: Danilo Rodríguez. Intérpretes Mónica Romero, Camilo Molina y Raisa Cubillos. Bogotá. 2019

Nos permitimos encontrar otras narrativas que estén acorde a nuestras búsquedas de mujeres solidarias y presentes en al árbol genealógico de las pioneras, y de la construcción de caminos diferentes a los que nos cuenta la historia oficial en un ejercicio de escarbar profundamente otros registros. Pues la danza, en su función expresiva revela estados profundos de la sociedad y sus corporeidades en una relación dialéctica entre las lecturas individuales y las sociales.

Indudablemente, traer a María a nuestra memoria corporal es un acto de sanación con el pasado que poco se conoce y con la vida de una mujer que instigada por el silencio lucha contra el olvido. Lo que nos convoca a hacer un ejercicio de memoria que pase por reconocer la mirada que construimos desde esta época: aprehensión de la realidad kinésica. No hay Estudios de la Paz y el Conflicto, Revista Latinoamericana, IUDPAS-UNAH, Número Especial 1, 2019, pp. 85-101. DOI: 10.5377/rlpc.v0i0.9505 
equívoco en pensar que somos sujetas históricas y como tales reconocemos e invocamos a las mujeres que lucharon por el derecho a alzar la voz, pronunciarse y participar con libertad en la vida; urdimbre que nos posibilita ser nosotras mismas.

Esta lectura contemporánea contempla la complejidad histórica e interseccional sobre el ocultamiento de las ideas de las mujeres como un acto para resguardar y mantener el orden de conquista de unos cuerpos sobre otros. De modo que, este trabajo es expresamente un acto político de unión, amor por la vida y por el derecho a recordar y ser recordadas. Es, en efecto, una conversión de la ausencia producida, a la presencia potencial. Pasamos, entonces, de una estética del ocultamiento a una estética del reconocimiento como posibilidad de reconciliación y lucha contra el olvido, el silenciamiento y la ausencia producida.

\section{Matizar la mirada: un camino de reconciliación con la historia negada.}

En el puerto de silencios, ocultamientos y ausencias que han marcado nuestra historia como sujetas colombianas y globales, encontramos unas preguntas centrales que nos atraviesan: ¿cómo recordar nuestra historia pasada y reciente? ¿qué contar para recordar? ¿quién/quiénes narran estas historias? El interés por sumergirse en las respuestas a estos interrogantes dentro del proceso de creación-investigación en danza nos trazó un horizonte de significaciones que traen como antesala la reconciliación con la historia múltiple, es decir, con las historias negadas.

Las prácticas de ocultamiento y el peligro de contar una sola historia nos incorporaron en estados de conocimiento y reconocimiento de memorias que ampliaron nuestra mirada de mundo y nos brindaron nuevos matices desde la perspectiva interseccional. En este ampliar la mirada como apuesta reflexiva-corporal, develamos un secreto dicho a voces, a saber: la historia oficial de Colombia tiene como protagonistas a los grandes héroes libertadores y colonizadores, en su totalidad hombres, que partían de una dinámica guerrerista para construir y consolidar la idea del Estado-Nación y la modernidad colonial.

Dicha construcción hegemónica de la memoria quisimos transgredirla y en este proceso de interpelación acogimos la siguiente premisa: quien conoce y reconoce su historia tiene la posibilidad de transformarla y (re)crearla. Esta pauta logró reconciliarnos por medio de la danza con las ucronías de la narrativa histórica que fueron producidas como inexistentes. Ejemplo de ello lo encontramos en la vida de María Cano y en el rol de la mujer en las luchas sociales desde la relación sexo-género/raza/clase en Colombia.

Así pues, nos reconciliamos con un pasado que aparece ausente, pero tiene la potencialidad de contener múltiples voces y universos de significación. Nos reconciliamos con una temporalidad que no se encuentra determinada, sino que la construimos en una poética de la relación. Nos reconciliamos con una historia agridulce marcada por el dolor y la grieta. Nos reconciliamos con la historia fisurando, un poco, el muro colonial de la memoria y el olvido.

Sabemos que este trabajo de paz contribuye a la emergencia de un sujeto político consciente y agente de su historia. De modo que reconociéndonos y autodenominándonos como mujeres sabemos que nuestra historia femenina no comienza con nosotras ni con nuestra muerte, sino es un costurero hecho con los hilos de la vida. Pues es en la búsqueda de nuestras antepasadas que nos encontramos con nosotras mismas. Diremos, entonces, una y otra vez: todas y todos somos María Cano, pues aún tenemos la palabra. 


\section{María Cano en la mutación del cuerpo. De la estética del ocultamiento a la memoria estética}

Aproximarnos a María Cano desde la danza nos evocó las siguientes preguntas: ¿Cómo rastrear desde una aproximación sensible la vida de María Cano? y ¿cómo relacionarnos espacio-temporalmente con el inicio del siglo XX desde el hoy? Cuestionamientos que implicaron, por un lado, disponer todos los sentidos para encarnar la vida y lucha de María, y por otro, comprender la realidad kinésica y sensitiva de su vida y su contexto; teniendo en cuenta que las inquietudes y disposiciones corporales contemporáneas cargan ciertas diferencias con respecto a la época de esta mujer. A su vez, esto nos llevó a la noción de memoria estética como ejercicio creativo y reflexivo en el que recogimos diferentes fuentes de información sobre María para recrear y confrontar su existir con nuestra propia experiencia.

Acudimos al texto "Tocando la historia" de Ann Cooper Albright (2014) quien brinda algunas pistas sobre cómo podemos ser tocados por la historia y cómo, desde el cuerpo, podemos volver sobre una temporalidad pasada. La autora manifiesta que el ser "tocado" se presenta como lugar de frontera e intercambio, abriendo un camino de experiencia perceptual para conocer y remitirnos a otros estados espacio-temporales. Estos refieren a la Colombia del siglo XX donde cobraban fuerza escenarios como las plazas de mercado; estaciones del tren; territorios marcados por guerras y violencia; valles y montañas andadas en burro, barco o a pie; y lugares de congregación política.

En ese lugar fronterizo consideramos pertinente entrar a la vida de María, de manera que nos permita no solo confrontarnos, sino también darle cabida a la confluencia de nuestra historia con la de ella, así como las disposiciones corporales que constituyen a una época específica. Lo anterior tiene una amplia gama de matices que es preciso reconocer y cuestionar a la luz de nuestra contingencia y transformación como sujetas en el presente: hacer un ejercicio de memoria estética. Disponer el cuerpo desde el hoy implica reconocer nuestro contexto y nuestra propia realidad que como personas vivimos, percibir con todos nuestros poros y sentidos un pasado de la historia colombiana. Por lo que no solo es reconocernos como sujetas, sino también estar de cara a un presente de manera transformada.

Nos proponemos entonces pasar de una estética del ocultamiento a una estética del reconocimiento, percatándonos de que esta estética del reconocimiento implica un ejercicio de reconciliación. Es decir, no pasar solamente por la visibilización de la vida de una mujer que movilizó luchas en favor del bienestar de la población colombiana, sino pasar por el cuerpo para comprender que este silencio al que la arrojaron también lo hemos padecido, ya sea por omisión en la historia oficial, o porque las mismas fuerzas que la silenciaron permanecen con otras formas en este siglo.

La práctica desde donde nos ubicamos para hacer este ejercicio que hemos llamado de reconciliación es la danza-teatro ${ }^{6}$, la cual tiene un componente de exploración corporal y escénico bastante amplio. Tanto en los entrenamientos, exploraciones y momentos de

\footnotetext{
${ }^{6}$ Danza-teatro: género de danza acuñado por la coreógrafa Pina Bausch donde el cuerpo y el movimiento construyen una dramaturgia corporal que permiten lecturas desde el gesto, la acción, la palabra y la significación de los objetos en escena. El método de collage utilizado dentro de la composición permite, a través de cuadros, intercambiar el orden sin perder el sentido del mensaje final. Además, los bailarines son creadores desde su experiencia corporal, convirtiendo la experiencia escénica en un espacio para la autorreferencialidad y la búsqueda de caracteres que permitan transitar por los personajes de la vida de María y su época.

Estudios de la Paz y el Conflicto, Revista Latinoamericana, IUDPAS-UNAH, Número Especial 1, 2019, pp. 85-101. DOI: 10.5377/rlpc.v0i0.9505
} 
creación, como en la escena, la vida de María Cano no cesa de hablarnos y preguntarnos. Así lo experimentamos cuando, por ejemplo, realizamos el dueto de la María pública y la María privada. En el momento de creación entramos a indagar corporalmente dos fuerzas, dos tonos: lo grácil de la María privada y lo robusto de la María pública. Del encuentro repetitivo de estas dos Marías, comenzaron a emerger comprensiones sensibles y epistémicas de ser una mujer sindicalista en ese contexto:

"La fuerza de la joven María, la flor del trabajo ovacionada por todos los trabajadores de la época, sostiene a la vieja María silenciada, expulsada del partido obrero, desdeñada incluso en el lenguaje (...). Esta lucha de fuerzas busca, desde nuestro cuerpo que es el cuerpo de la María robusta y resistente, no dejar caer en el silencio a esa María -grácil y vulnerable-". (Daniela García y Karen Fajardo. Relatos etnográficos: "Danza a dos cuerpos, la María pública y privada", 2019).

La repetición que implica todo montaje escénico, pasar varias veces la "misma" información por el cuerpo, nos abrió varias perspectivas en torno a las implicaciones que tiene traer sensiblemente esta mujer al presente; pues,

“(...) En esta resistencia no se siente sólo la fuerza de María, sino también la fuerza de las mujeres contemporáneas que la traen a la memoria, al lenguaje, a la academia, a la política, y al cuerpo”. (Daniela García y Karen Fajardo. Relatos etnográficos: "Danza a dos cuerpos, la María pública y privada", 2019).

\section{Fotografía 3. El vuelo de María.}

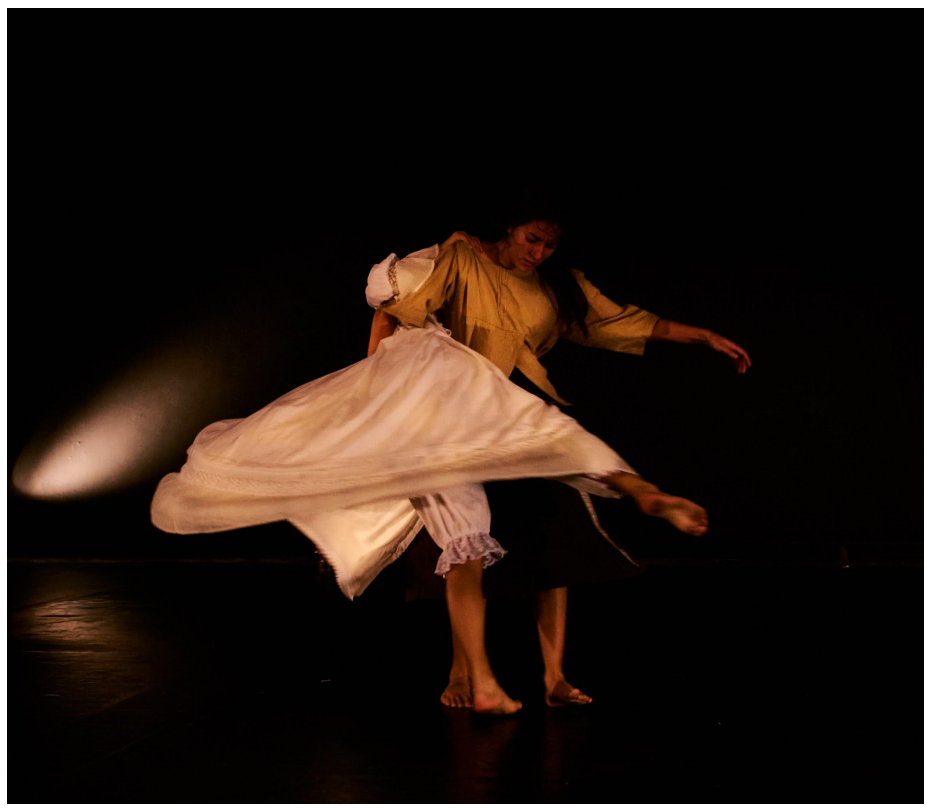

Fuente: Danilo Rodríguez. Intérpretes Karen Fajardo y Daniela García. Bogotá. 2019

Cabe aclarar que esta práctica artística, como todo arte, no puede tener un fin instrumental, de modo que no pretendemos con este proyecto sostener que la danza transforma de forma redentora las experiencias de violencia. Por el contrario, partimos de la danza desde su función expresiva, que nos permite comprender realidades desde la pregunta, desde la exploración, descomponiendo y creando desde el juego otras perspectivas de dichas realidades. 
En este caso, la danza en su función expresiva nos permite redefinir un pasado que es preciso traer al presente. Por un lado, el pasado al que nos remitimos nos ubica como sujetos o sujetas históricas (en los enunciados de ser mujer, ser colombiana, ser de clase media, etc), y por el otro, es un pasado que traemos al presente, a nuestros cuerpos y que por tanto lo actualizamos, y lo transformamos. En esto consiste la memoria estética, y como lo enunciamos más arriba, no puede ser abordada en términos lineales. Hemos encontrado que en nuestro ejercicio de memoria desde la danza confluyen distintas temporalidades, distintos espacios, y distintas sujetas.

El ejercicio de memoria pone de facto que somos seres, cuerpos en devenir constante. En este devenir no podemos simplemente hilar unos hechos cronológicamente y llamarlo memoria, esto es tan sólo la parte visible, el plano en el que nos vemos como sujetas separadas y distintas de lo otro (sean personas o cosas). En la parte invisible, no tan obvia, nos vamos componiendo en flujo con otros flujos, lo cual, según Rolnik, es violento, pues el devenir implica la desestabilización y creación de un nuevo cuerpo (Rolnik, 1993: 2). En el proceso de investigación-creación de María Cano. Aún tengo la palabra esta desestabilización no sólo es constante, sino que es ineludible para su realización. Una de las primeras exploraciones fue grupal, y ponía en el centro un objeto muy común en el contexto antioqueño que vio crecer a María: el costal cafetero.

\section{Fotografía 4. Costal en juego.}

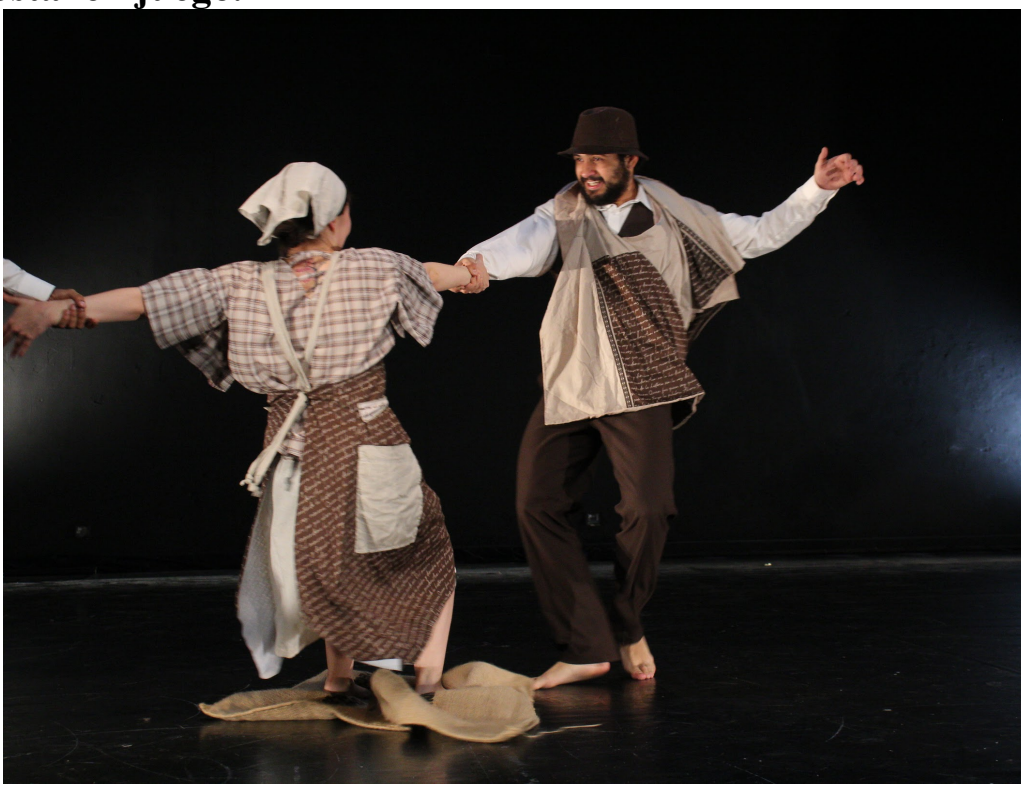

Fuente: Danilo Rodríguez. Intérpretes Mónica Romero y Ricardo León. Bogotá. 2019

“(...) El lenguaje común que nos suscitó el trabajo con el costal, a saber: la huida y sus usos cotidianos (el juego y el trabajo) (...). Así, desde el ejercicio práctico de situar el cuerpo en un estado de huida fueron emergiendo similitudes de sentidos y estados fisico-sensitivos vívidos. Estados referentes al estar en fuga, en ocultamiento, en un contexto de represión específico. (Mónica Romero. Relatos etnográficos: "Ocultamiento y fuga. Relatos corporales, asunciones soterradas", 2019).

Devenir estos cuerpos en fuga, desde una puesta en escena, requiere re-crear esos modos de ser en el cuerpo, in-corporarlos. Incluye el miedo de caer, la oscuridad dentro del costal, Estudios de la Paz y el Conflicto, Revista Latinoamericana, IUDPAS-UNAH, Número Especial 1, 2019, pp. 85-101. DOI: 10.5377/rlpc.v0i0.9505 
el riesgo de confiar en la otra, pero también la determinación de saltar, el alivio de salir del costal y la posibilidad de confiar tu cuerpo a otra. Cada vez que debemos crear un nuevo cuerpo, un nuevo modo de sentir, pensar, existir, nos estamos volviendo otros. Pero lo más interesante es que en el preludio de esta transformación nos encontramos en un estado extraño, vivimos la diferencia en nosotras, en nuestros cuerpos. La sensación de extrañamiento y de diferencia consigna la exigencia de sacarnos de nosotras mismas. Este estado tiene una gran potencia creativa, ya que funda una apertura que debe ser trabajada para que de allí emerja un nuevo cuerpo.

"Asi pues, fuimos cuerpos que se ocultan estando expuestos, fuimos cuerpos que huyen para defenderse y se defienden para vivir, fuimos cuerpos que quisieron silenciar, pero en sus intentos, sacaron con mayor intensidad su grito, su voz y su aliento". (Mónica Romero. Relatos etnográficos: "Ocultamiento y fuga. Relatos corporales, asunciones soterradas", 2019).

Este estado de extrañamiento no se presenta pocas veces, todo el tiempo las personas estamos encontrándonos con la diferencia. Podríamos omitir esa sensación incómoda y cerrarnos a esos otros que se nos presentan desde una clara diferencia espacio-temporal, sin embargo, la creación en danza implicó un profundo estar dispuesto corporalmente. El trabajo de nosotras está en dejarnos extrañar por esta diferencia y crear un sentido que permita su existencia en el cuerpo (Rolnik, 1993). A partir de esta comprensión de transformación que trabaja Rolnik, la temporalidad cambia y por tanto cambia la comprensión de memoria, "estamos distantes de la memoria de las cosas o las representaciones, memoria del pasado en cuanto ya existido" (Rolnik, 1993: 4). Es comprender una memoria que se hace con el cuerpo, pero no el cuerpo visible, sino su estado invisible compuesto de flujos y devenires. La memoria como potencial generadora de nuevas trayectorias en el tiempo.

Ahora bien, hay unas prácticas que permiten que una entre a la propia experiencia de dichas marcas para dejar proliferar aquellas potencias transformadoras, es decir, crear un cuerpo que existencialise la diferencia. Desde su experiencia académica Rolnik habla de la escritura, ya que es un ejercicio en el que se pone en el orden de lo visible lo que ocurre en el plano de lo invisible, la diferencia. Por nuestra parte, hemos asumido un proceso múltiple cuya base es la danza, y es múltiple en tanto investigación-creación que vincula la escritura con la exploración corporal. Sin embargo, la práctica danzaria profundiza en un modo específico de ser: la dimensión estética.

El ejercicio de memoria estética como estrategia de paz, se fundamenta en la comprensión de la expresión estética como lugar primordial en la acción política. Para sustentar este punto, acogemos a la filósofa Chantal Mouffe $(2014,2016)$, la cual no establece una distinción entre arte y política, porque el arte constituye y reproduce unos órdenes simbólicos dentro de unas prácticas políticas específicas. Así, lo cultural se constituye como lugar decisivo en la conformación de lo hegemónico, y por tanto lugar decisivo para su deconstrucción.

Por un lado, las prácticas estéticas, específicamente críticas, son prácticas contra hegemónicas que intentan desarticular aquellas hegemonías sedimentadas y naturalizadas. En este caso entramos a desarticular las narrativas de la historia dominante, para develar, a través de la danza, la vida de una mujer que trazó caminos de las luchas que aún se pelean. Por el otro, trabajamos en la creación de un arte crítico en el que se fomenta el disenso, haciendo visible todo lo reprimido por el consenso dominante. Al comprender que el conflicto es inherente a las dinámicas sociales, y que genera múltiples emociones y afectos, el arte danzario se presenta como un lugar alternativo de canalización o manifestación de 
dichas pasiones. Defendemos la danza como una estrategia de paz, al permitir una vía no violenta a la manifestación del disenso y una transformación de las experiencias desde el cuerpo en movimiento.

\section{REFLEXIONES FINALES}

María Cano, como arquetipo, nos aproximó — desde el lenguaje corporal e investigativoal sumario de prácticas de ocultamiento y silencios que alimentan la línea abissal de exclusiones; línea que produce sujetos, marcos de referencia de mundo y temporalidades como escenarios posibles o inexistentes. En la Colombia de inicios del siglo XX y en la actualidad, esta marca continúa, aunque con diferentes matices, produciendo sujetos fronterizos ante la jerarquía de poder, tal es el caso, de Cano y de tantas mujeres que fueron silenciadas y ocultadas de la historia oficial.

Lo explorado en este proceso creativo abrió un horizonte de sentidos a nivel corporal y lingüístico instado por la vida de una gran mujer que construyó su vida política, tanto pública como privada, desde la subalternidad, la historia múltiple y el intento de transgredir los patrones de dominio y control de unos cuerpos sobre otros. Así, nuestra propuesta de narrar a través del movimiento se encuentra instigada por una lucha contra el silencio, el olvido y la centralización de una historia unívoca, falocéntrica y colonial.

Nos permitimos, en ese sentido, aprehender como estrategia de reconciliación y sanación otras maneras de reconocer y narrar las historias múltiples, a sabiendas que la danza se nos presentó como un camino expresivo y, en nuestro caso, transgresor. Una vez asumido el compromiso nos interpelamos temporalmente en el ir y venir pasado-presente explorando las afonías y alteridades que nos constituyen como personas y como mujeres nacidas en este territorio. Lo anterior, nos convocó a releer la vida de María de los Ángeles, su acción política y ética para hacerle preguntas, problematizar y reflexionar, y en simultáneo volverla un acto creativo y expresivo con el cuerpo y el movimiento hecho danza: hacer un ejercicio de memoria estética.

Aunado a ello, durante el proceso de investigación-creación en danza, de exploración de las disposiciones corporales y en la composición de imágenes surgió la pregunta: ¿cómo replantear un presente con responsabilidad histórica, dejando de lado las retóricas que excluyen al cuerpo? Pues vemos en él una herramienta, una mediación activa, un signo social, cultural y artístico, ya que permite verbalizar y construir realidad cumpliendo una función narrativa.

Esta descomposición y creación de otras perspectivas desde la danza no es un trabajo de poco alcance, pues también comprendemos que el arte constituye y reproduce unos órdenes simbólicos dentro de unas prácticas políticas específicas. Así, lo cultural se constituye como lugar de disputa en la conformación de lo hegemónico, y por tanto lugar decisivo para su deconstrucción.

Lo cual nos llevó a preguntarnos ¿Cómo la práctica de creación en danza podría llevar a una deconstrucción de este tipo? Y aunque esta pregunta continúa abierta, comprendemos que, al ir hacia María Cano, una otra que es pasado, debemos crear un cuerpo, un nuevo modo de sentir, pensar y existir en el que la diferencia de esa otra exista. Sin embargo, la vida comprende constantemente encuentros con otros, con pasados, etc, pero esto no quiere decir que a partir de ellos nos transformemos. Asumir el trabajo investigativo en este proyecto 
creativo es el que ha permitido que nuestra disposición esté abierta a dejarnos extrañar por esa diferencia y crear sentidos que permitan su existencia en el cuerpo.

En danza esta disposición se abre en cada momento de exploración y creación, cuando, por ejemplo, observando la vida de una mujer sindicalista a inicios del siglo XX nos asumimos como tal, con su fuerza y su palabra. Este ejercicio de asumir, desde lo performativo, ser la María del discurso y la María en el silencio, ser las mujeres de las textileras y las mujeres que impugnaron contra María, ser el campesino trabajador y el obrero abnegado; implicó la creación constante de cuerpos que asumen dichas diferencias para volvernos otras. Pero no otras sólo en la escena, en la función o en el ensayo, sino otras en el mundo que nos acontece hoy.

\section{REFERENCIAS}

Adokarley, B. (2015). El sexismo lingüístico e implicaciones reformistas para la lengua. Una perspectiva crítica del español y un estudio colateral del Ga. Tesis Doctoral. Universidad Nacional de Educación a Distancia, UNED, Madrid.

Albright, A.C., (2014). “Tocando la historia”. En Sanabria, C. y Ávila, A. (Eds.) Pensar con la danza. Bogotá: Ministerio de Cultura de Colombia, Universidad de Bogotá Jorge Tadeo Lozano, 33-40.

Antonacci, M.A. (2016), “Decolonialidad de cuerpos y saberes”. En Gandarilla, J. Guadalupe (Ed.). La crítica en el margen. México: Akal.

Cameron, D. (1985). "What Has Gender Got to Do With Sex?", Language \& Communication, 5(1), 19-27.

Cameron, D. (1992). Feminism and Linguistic Theory. New York: Palgrave Macmillan.

Bidaseca, K. (2018). La Revolución será feminista o no será. La piel del arte feminista descolonial. Buenos Aires: Prometeo.

ENS (Escuela Nacional Sindical) (2007). María Cano, 1887-2007 una voz de mujer les grita. Medellín: ENS.

Gallor, P. (1988). "Maria Cano, un ejemplo a Seguir”, Universitas Humanística, Vol 17 N. 29, 289-294.

Mouffe, C. (2014). Agonística pensar el mundo políticamente. Buenos Aires: Fondo de Cultura Económica.

Mouffe, C. (2016). La paradoja democrática: El peligro del consenso en la política contemporánea. Barcelona: Gedisa.

Norbeck,H. (2013). El sexismo en el lenguaje: Estudio de los sustantivos de profesión. Universitetet i Tromsø.

Robledo, B.H. (2017). María Cano. La virgen roja. Bogotá: Debate.

Rolnik, S. (1993). "Pensamento, corpo e devir: uma perspectiva ético/estético/política no trabalho académico", Cadernos de subjetividade, 1(2), 1-15.

Rudolf, L. (1994). Danza educativa moderna. Barcelona: Paidos Ibérica.

Sousa Santos, B. (2010). Descolonizar el saber, reinventar el poder. Montevideo: Ediciones Trilce-Extensión Universitaria de la Universidad de la República.

Sousa Santos, B. (2018a). "Introducción a las Epistemologías del Sur”. En Meneses, M., y Bidaseca, K. (Coords.) Epistemologías del sur. Buenos Aires: CLACSO, 25-62.

Sousa Santos, B. (2018b). Aula 2- construção de diálogos entre saberes a partir das epistemologias do sul. Na oficina do Sociólogo artesão. Aulas 2011-2016. São paulo.

Estudios de la Paz y el Conflicto, Revista Latinoamericana, IUDPAS-UNAH, Número Especial 1, 2019, pp. 85-101. DOI: 10.5377/rlpc.v0i0.9505 
Trouillot, Michel-Rolph (2011). “Universales nordatlánticos: ficciones analíticas, 14921945”. En Dube, S. (Ed.) El encantamiento del desencantamiento: historias de la modernidad. México: Colegio de México, Centro de Estudios de Asia y África, 49-72.

\section{REFERENCIA DE LAS AUTORAS}

Marybel Acevedo Fandiño. Maestra en Artes Escénicas con énfasis en Dirección Coreográfica de la Universidad Francisco José de Caldas. Investigadora en Historia de la danza en Colombia. Su trabajo se caracteriza por formular proyectos de creación y pedagogía para Universidades y organizaciones como Unicef y Banco de Proyectos de la Secretaría Distrital de Cultura y Turismo. También ha realizado producción y gestión de festivales de danza. marybelacevedo@gmail.com. ORCID: https://orcid.org/0000-0002$\underline{8850-5120}$

Karen Fajardo Capador. Filósofa en proceso de grado de la Universidad Externado de Colombia, formada en investigación social con énfasis en cultura, sociedad y poder, área donde ha investigado sobre filosofías no-occidentales, éticas antiguas, y especialmente la relación estética-política. Bailarina intérprete y creadora del colectivo Extémpora Danza. krenfajardo@gmail.com / karen.fajardo@est.uexternado.edu.co. $\quad$ ORCID: https://orcid.org/0000-0002-4138-0439.

Daniela García Hernández. Antropóloga egresada de la Universidad Externado de Colombia con énfasis en Salud, conocimientos médicos y sociedad. Investiga áreas afines a la lingüística, etnohistoria, memoria, estética, devenir y ecología. Bailarina intérprete y creadora del colectivo Extémpora Danza. dali.gahe@gmail.com. ORCID: https://orcid.org/0000-0003-1540-5054.

Mónica Alejandra Romero Pérez. Socióloga egresada de la Universidad Externado con énfasis investigativa en conflicto y dinámicas socioterritoriales. Especialista en curso en Epistemologías del Sur del Consejo Latinoamericano de Ciencias Sociales (CLACSO) y Centro de Estudios Sociales - CES Portugal. Bailarina intérprete y creadora del colectivo Extémpora Danza. monica.romerop1@gmail.com. ORCID: https://orcid.org/0000-0003$\underline{4437-9043}$

Mariana Velandia Nova. Psicóloga en proceso de grado de la Universidad Externado de Colombia con formación interdisciplinar y en investigación social; con énfasis en procesos sociales, territorios y medio ambiente; asociada a temas de investigación en género, teorías queer, sexualidad, sistemas de vida, salud mental, procesos de vinculación e interacción social. Bailarina intérprete y creadora del colectivo Extémpora Danza. mariana.velandia@est.uexternado.edu.co ORCID:https://orcid.org/0000-0002-2675-4762

Recibido: 27-01-2020

Aceptado: 10-02-2020

$$
\text { (c) (i) Licencia Creative Commons Reconocimiento 4.0 (CC BY 4.0). }
$$

Estudios de la Paz y el Conflicto, Revista Latinoamericana, IUDPAS-UNAH, Número Especial 1, 2019, pp. 85-101. DOI: 10.5377/rlpc.v0i0.9505 